\title{
Interactive comment on "A comprehensive dataset of vegetation states, fluxes of matter and energy, weather, agricultural management, and soil properties from intensively monitored crop sites in Western Germany" by Tim G. Reichenau et al.
}

\section{Anonymous Referee \#1}

Received and published: 27 April 2020

I appreciate that the editor has offered this opportunity to comment. In this manuscript, Reichenau et al. present a comprehensive dataset of vegetation states, fluxes of matter and energy, weather, agricultural management, and soil properties from four intensively monitored crop sites in Western Germany. The authors are to be commended for undertaking an ambitious project and providing types of data useful to the agriculture and the authors specified the detailed uncertainty and quality assurance of each dataset, 
which is not usually seen in many published datasets. I think this dataset and paper are worth publishing in ESSD. However, there are some major or minor information needs to be clarified before its acceptance and publication.

1. These sites are/were intensively agricultural sites. As an ecosystem modeler, considering the purpose of initializing crop/ecosystem models, the pre-management vegetation and soil conditions (e.g., soil $\mathrm{C}$ and $\mathrm{N}$ content, potential vegetation type and its states) should be used to initialize models. However, the data regarding vegetation and soil properties provided in this paper are quite contemporary, say time coverage is from 2007 to 2017 . The initial conditions of vegetation and soils were missed in these sites. Is it possible to add some of the background information to make the dataset more complete?

2. Under section 5, please specify the beginning and ending date of the 15 time series. I went over the spreadsheet and found the temporal coverages of these time series are not even. Still, it is amazing to see the 30 -min interval data!

3. Under section 7, four different gap-filling methods were actually used. However, the reasoning of each method every time it is used at different sites is not explicit enough. Under what circumstances each method was exactly used? And why?

\section{Minor comments:}

The current organization of the paragraphs is not good enough. There is no first-line indentation where it is needed. Bullet points also do not have indentations. Some sloppy spelling and wrongly used punctuation and marks. Also, no line number, which makes it hard to specify comments.

Section 2.1 Line 11: within the parenthesis, \% was used while degree was used in other places. Be consistent. Line 19: data is a plural term!

Section 2.2 Line 25, degree sign is used here. Be consistent.

Section 2.3 Last line: what is the temporal range for the mean annual temperature of

Interactive

comment

\section{C2}

Printer-friendly version

Discussion paper

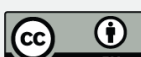


9.7 degrees in this site?

Section 3 Line 10: data is a plural term! Line 15: remove "and" before "can thus be"

Section 4.1 Line 4: remove "given"

Section 5.1 Line 20: please use subscript for $\mathrm{H} 2 \mathrm{O}$ and $\mathrm{CO} 2$.

Section 7.1.1 Line 30: please specify the years for the sites for which the EOF method was applied.

Page 16 Line 6: please correct the " and " signs.

Interactive comment on Earth Syst. Sci. Data Discuss., https://doi.org/10.5194/essd-2019-193, 2020. 